\title{
REESCRITURA CINEMATOGRÁFICA DE UNA ZARZUELA EN CLAVE ESPERPÉNTICA: LA CORTE DE FARAÓN, DE JOSÉ LUIS GARCÍA SÁNCHEZ Y RAFAEL AZCONA ${ }^{1}$
}

\author{
THE CINEMATOGRAPHIC REWRITING AS AN ESPERPENT \\ OF THE ZARZUELA LA CORTE DE FARAÓN, \\ BY JOSÉ LUIS GARCÍA SÁNCHEZ AND RAFAEL AZCONA
}

\author{
José SEOANE RIVEIRA \\ Universidad de Salamanca \\ seoaneriveira@usal.es
}

Resumen: Con el advenimiento del primer gobierno socialista en España y el fin de la censura, el cineasta salmantino José Luis García Sánchez escribe, junto a Rafael Azcona, un guion cinematográfico tomando como hipotexto la zarzuela La corte de Faraón, de Perrín y Palacios (1910). Las estrategias narrativas utilizadas para esta reescritura fílmica de un espectáculo teatral están estrechamente relacionadas con el esperpento, y produjeron no solo resultados curiosos e interesantes en el ámbito del cine sainetesco y esperpéntico, sino que definieron a partir de sus características formales la época de cambio político, social y económico más relevante de la historia española reciente. Este artículo analiza las transformaciones

\footnotetext{
${ }^{1}$ Este artículo es resultado del proyecto de investigación "Intermedialidad e institución. Relaciones interartísticas: literatura, audiovisual, artes plásticas”. Referencia HAR201785392P. Investigadores Principales: Dr. Fernando González García y Víctor del Río García.
} 
operadas por ambos guionistas sobre la obra original a nivel narrativo para adecuarla a un sistema semiótico distinto al del teatro, y las técnicas cinematográficas utilizadas por el cineasta para otorgar sentido a su nuevo texto visual.

Palabras clave: La corte de Faraón. Zarzuela. Cine. Reescritura. Esperpento. La corte de Faraón.

Abstract: With the income of the first socialist government in Spain and the end of the censorship, the Salamanca-born filmmaker José Luis García Sánchez writes, in colaboration with Rafael Azcona, a script which takes as hypotext the zarzuela La corte de Faraón, by Perrín y Palacios (1910). The narrative strategies that were used for this rewriting of a theatrical performance are closely related to esperpent, and they produced not only some curious and interesting results in the field of sainetesque and grotesque spanish cinema, but also defined with its forms an era of huge political, social and economic changes of the recent history of Spain. This paper analyzes the transformations that both screenwriters operated from the original work at a narrative level in order to adapt it to a new semiotic system, different from the theater, and the cinematographic techniques that the filmmaker used to give meaning to his new visual text.

Key Words: La corte de Faraón. Zarzuela. Cinema. Rewriting. Esperpento.

\section{PRELIMINAR}

Desde su exitosa ópera prima Las truchas (1978) hasta el rodaje de La corte de Faraón (1985), el cineasta salmantino José Luis García Sánchez se mantuvo alejado de la actividad cinematográfica, si se obvia el documental militante Dolores (1980), acerca del regreso de la Pasionaria al País Vasco tras su exilio durante la dictadura. A pesar de que a lo largo 
de aquellos casi diez años en los que abandonó la dirección de cine de ficción, García Sánchez continuó trabajando como ayudante de Basilio Martín Patino y no se embarcó en un nuevo filme propio hasta que dio por terminado el proceso de la Transición política en España y consideró que la censura estaba totalmente finiquitada. Hasta aquel entonces no hubiera podido, según él, rodar con libertad, ya que, en sus propias palabras, "la censura desaparece oficialmente en 1979-1980” (De la Torre, 2016: 156), no antes. La Transición hacia la democracia había terminado y el PSOE ganaba las elecciones de 1982, lo que abría un panorama de expectativas renovadas en todos los ámbitos y, especialmente, en el cultural y el cinematográfico.

Con el Partido Socialista en el gobierno, los esfuerzos por renovar la industria cinematográfica española se vieron plasmados en un decreto ideado fundamentalmente por Pilar Miró, por entonces Directora General de Cinematografía. Los objetivos de la nueva remodelación de la industria del cine en España eran los de propiciar nuevos proyectos, más ambiciosos y con más posibilidades económicas, que situasen al país en el panorama europeo y elevasen sustancialmente la calidad general de las producciones españolas. Como ella misma señalaba sobre el objetivo de su decreto, este "no [era] otro que el de conseguir una industria española fuerte, sólida, transparente y estable, que pueda competir y aprovechar las ventajas que sin duda se derivan de la incorporación a la Comunidad [Económica Europea]" (Riambau, 1995: 400)2.

Para ello, el modelo que se tuvo en cuenta fue el francés y se tomaron medidas fundamentales en los apartados de la producción, de la distribución y de la exhibición. En lo tocante a la producción, se introdujo una subvención anticipada según el plan de producción y se estipulaban ayudas especiales para películas con un presupuesto superior a 55 millones de pesetas; en cuanto a la distribución, la tasa de licencias de doblaje se rebajó a cuatro por cada película española y posteriormente a tres (Castro de Paz y Pena, 2005: 257-259).

${ }^{2}$ Declaraciones recogidas por Riambau de Pilar Miró a El País el 12/07/1985. 
Con este tipo de normativa, la industria fue privilegiando la figura del productor, con lo que experimentó un auge el perfil director-productor. Muchos proyectos, además, se presentaban considerablemente "inflados" en sus presupuestos para superar la barrera de los 55 millones de pesetas y conseguir de este modo la ayuda especial. Por otra parte, la irrupción de TVE en el campo de la producción dio paso a "la creación de adaptaciones literarias de clásicos hechas por cineastas de prestigio que pretendía imitar la senda de la BBC y las grandes cadenas públicas europeas", además de permitir el "desarrollo de un cine literario de qualité3, con factura primorosa y, en algunos casos, rentabilidad comercial, [y] los anticipos económicos por los derechos de emisión de las películas en televisión se convirtieron en una fórmula esencial de financiación". Este contexto legal trajo como consecuencia que el estilo de los filmes se equiparase y obedeciese a la narrativa clásica cinematográfica, ya que los criterios para conceder ayudas no eran solo políticos o económicos sino también estéticos (Benet, 2012: 397-398).

\section{LA CORTE DE FARAÓN: REESCRITURA DE UNA ZARZUELA CON GUION DE RAFAEL AZCONA}

En esta situación político-cultural es cuando se produce la primera colaboración entre Rafael Azcona y José Luis García Sánchez. El guionista riojano, ya afincado en Madrid, fue escogido por el cineasta castellanoleonés una vez que Luis Sanz, productor y mánager de Ana Belén, le ofreció a él dirigir el proyecto, que trataría sobre la zarzuela La corte de Faraón (1910), de Guillermo Perrín y Miguel de Palacios, con música de Vicente Lleó. La zarzuela4, con elementos claros de la opereta y la revista, puede considerarse una parodia sicalíptica (por las constantes connotaciones sexuales de los diálogos y la trama erótica) de la Aida de Verdi. La trama

\footnotetext{
${ }^{3}$ La cursiva es mía.
}

${ }^{4}$ Sobre la actualidad de género, puede verse el apartado que se le dedica en José Romera Castillo, ed. (2016), Teatro y música en los inicios del siglo XXI. 
transcurre en el Egipto de la época Faraónica: Putifar, un general, vuelve victorioso y el Faraón lo recibe y le entrega como prometida a Lota por su valor y servicios. Sin embargo, Putifar ha sufrido una herida de flecha en sus genitales, por lo que no puede satisfacer sexualmente a su nueva esposa. Por ello, compra a un esclavo, el casto José, y se lo regala. Ante el atractivo sexual del esclavo, la propia Lota e incluso la esposa del Faraón se pelean por él. Finalmente, incluso el Faraón queda tan impresionado por las cualidades de José que lo nombra virrey.

La zarzuela, cuya aria ; $A y, b a$ ! es una de las más populares y representadas del género chico, además de himno oficial de la Irreal Academia del Esperpento ${ }^{5}$, suponía un escaparate inmejorable para el lucimiento de una Ana Belén cuya carrera se encontraba en auge. El propio director señalaba, en relación al primer plano en el que la actriz canta el aria, que en ese momento estaba "en el esplendor máximo de su belleza y había que retratarla" (De la Torre, 2016: 155). Esta colaboración entre Ana Belén y García Sánchez se volverá a repetir en Divinas palabras (1993) y en otras muchas películas, y no solo a nivel actoral sino también interpretando canciones, lo cual afectó de modo crucial al tono de la adaptación de la Tragicomedia de aldea. De hecho, el director salmantino achaca a su amistad con Ana Belén la llamada que recibió del productor Luis Sanz para realizar La corte de Faraón:

${ }^{5}$ La Irreal Academia del Esperpento (IAE) se constituyó el 3 de marzo de 2011 en el Café Literario y Bistró Max Estrella. Alonso Zamora Vicente fue nombrado, póstumamente, presidente a perpetuidad, y el resto de los miembros son: el dramaturgo y periodista Ignacio Amestoy, la periodista Rosana Torres, el catedrático Javier Huerta, el autor teatral Luis Aráujo, el crítico Enrique Centeno, Chatono Contreras, la actriz y cantante Karola Eskarola, el dramaturgo Manuel Gómez, el arquitecto y presidente del Círculo de Bellas Artes Juan Miguel Hernández de León, el escritor Ramón Irigoyen, Jesús Miranda de Larra, el poeta y exministro de Cultura César Antonio Molina, la actriz Esperanza Roy, el catedrático Jorge Urrutia, el crítico y escritor Javier Villán y, last but not least, el director de cine José Luis García Sánchez. El himno oficial de la IAE es el aria ¡Ay, ba!, de la zarzuela La corte de Faraón, ya que era una de las favoritas de don Ramón del Valle Inclán. Información extraída de la noticia "Nace la Irreal Academia del Esperpento", publicada en la sección de cultura de El País, el 04/04/2011, y recuperada el 17/05/2017 de https:// elpais.com/cultura/2011/03/04/actualidad/1299193214_850215.html [20/03/2018]. 
Cuando él ya empezaba a preparar La corte de Faraón, creo que él ya entonces sabía cómo iba a ir vestida Ana Belén. Él se buscaba el vestuario, un poco la iconografia y sobre todo las actrices. Quería hacerla con Ana Belén. Y yo creo que fui el primer director al que se la ofrecieron, pero no lo sé. Él se diría: ¿Quién es el director más cómodo para hacerla con Ana Belén? Uno que sea amigo suyo. Entonces, el director más amigo que tenía Ana Belén era yo, creo (De la Torre, 2016: 153).

La escritura del filme es responsabilidad total de Azcona y García Sánchez, que buscaban deliberadamente ajustar cuentas con la censura (De la Torre, 2016: 154). La "opereta bíblica” tuvo un éxito inmediato nada más ser estrenada en 1910, éxito que Peláez explica por cuatro razones: teatrales, socioculturales, políticas y económicas (2003: 2) que necesitan ser examinadas para entender mejor el funcionamiento del filme, en pleno auge del socialismo en España. Los motivos teatrales que llevaron al éxito inmediato (y duradero) de la zarzuela de Perrín y Palacios son los siguientes:

La entrada del siglo XX supuso la aparición de nuevas modalidades muy próximas al Género chico, pero con rasgos particularizadores: el género infimo, las variedades y la opereta. Básicamente añadian mayores dosis de espectacularidad, proyectaban en escena un erotismo más marcado, materializado en la figura de las actrices, y prestaban especial atención a los números musicales, cuya correcta ejecución era motivo suficiente para salvar del pateo a determinadas piezas que, sin duda, merecían el desprecio del respetable (Peláez, 2003: 3).

El fin de la censura a principios de los años ochenta provocó en España un "estallido" de erotismo a nivel popular: revistas y películas 
presentaban, de golpe, las carnes desnudas de sus protagonistas después de cuarenta años de censura. En el ámbito cinematográfico es notoria la presencia de una corriente de "explicitud", representada por filmes de categorías $S$ y $X$, cuyo mayor exponente fue Ignacio F. Iquino, y otra de "erotismo", en la que destaca Vicente Aranda, por ejemplo (Monterde, 1993: 163-164). Este fenómeno llevó al productor Luis Sanz a la recuperación de una zarzuela que, además de contener gran variedad de elementos picantes, otorgaba a Ana Belén la oportunidad de interpretar un papel a su medida. La nueva coyuntura política hizo que director y guionista, a partir de la premisa de la zarzuela, idearan un filme en el que ajustar cuentas con la censura. Esto nos lleva a las razones políticas que hicieron de La corte de Faraón un título emblemático del género chico en su época: en primer lugar, su prohibición por parte de los censores en la época de Alfonso XIII, que provocó que alcanzase su apogeo diez años más tarde, gracias a la afición por este género del dictador Primo de Rivera, y también su prohibición durante la posguerra por la dictadura franquista. Este hecho propició que se intentase su estreno por otras vías cambiando aspectos del argumento e incluso el nombre de la obra (Peláez, 2003: 6).

Por otra parte, la propia opereta bíblica parodiaba, en su forma original, varios tópicos del género operístico canónico, a través de la caricaturización de ciertas partes del argumento de Aida, de Verdi, y algunas alusiones a Madame Putiphar (Dupré y Forneau, 1897), que los espectadores de la época reconocían fácilmente, debido a que "el público español de principios del XX tenía una cultura teatral viva, a pesar de los elevados índices de analfabetismo, una cultura basada en los hábitos de asistencia a los teatros" (Peláez, 2003: 2). En el caso del filme de 1985, se parodian también, además de los temas de la propia zarzuela, la censura y el gobierno franquista.

Las causas económicas que propiciaban la aparición de zarzuelas como la que nos ocupa a principios de siglo XX eran varias: los directores de los teatros, ante el evidente éxito de público de este tipo de representaciones "picantes", en las que se entremezclaban a la perfección números musicales 
y diálogos, buscaban el estreno del mayor número de espectáculos de estas características. Por otra parte, el abaratamiento del precio de las entradas había provocado también una asistencia masiva de público a los locales donde se ofrecían este tipo de géneros desde finales del siglo XIX e inicios del XX (Espín, 1995: 74). ¿No podrían buscarse algunas concomitancias con la industria del cine durante la época socialista que se acaba de inaugurar con el decreto Miró, y con aquella "tercera vía" por la que García Sánchez había apostado en sus dos primeros filmes? ${ }^{6}$. La búsqueda de la rentabilidad industrial, la elevación de la calidad de las producciones nacionales y la asistencia de público a las salas fueron el objetivo primordial del nuevo gobierno socialista; y la conexión con la mayor cantidad de espectadores posible, usando un lenguaje cinematográfico tradicional pero también ofreciendo productos de calidad, era la meta que se había marcado García Sánchez desde sus inicios como cineasta. Si, tal y como demostró Zamora Vicente (1969), una de las influencias cruciales del esperpento valleinclaniano fue el género chico ya que este parodiaba hasta el ridículo otras obras más solemnes, en un filme esperpéntico de estas características ambas líneas de interés confluyen: la de una industria que busca mejorar su rentabilidad, representada por un productor como Luis Sanz, y la de un director que demanda su primera oportunidad real para ajustar cuentas con la censura y que se sirve de la parodia para llevar a cabo su empresa. La inclusión de Azcona para la escritura del libreto dotó a La corte de Faraón de muchos niveles de lectura, y de un tono esperpéntico todavía mayor que el de las primeras cintas de García Sánchez.

Existe, por lo tanto, cierta correlación entre los contextos de ambas obras, a pesar de haber sido estrenadas con prácticamente un siglo de diferencia, y de pertenecer una al género teatral y otra al cinematográfico

${ }^{6}$ El love feroz o cuando los hijos juegan al amor (1975) y Colorin, colorado (1976) estaban a medio camino entre la comedia subgenérica y el cine de autor de la época; a este tipo de cine, que buscaba un público urbano y cierta calidad sin caer en el intelectualismo se le denominó "tercera vía". Para más información, véase Torreiro (1995: 341-390). 
(ambos, principales espectáculos de entretenimiento para el gran público en sus épocas respectivas).

\subsection{Una narración fragmentada de filiación esperpéntica}

Desde este planteamiento, Azcona y García Sánchez presentan una historia que, lejos de adaptar la zarzuela en sí al medio cinematográfico, la toma como pretexto sobre el que construir otra trama argumental, ambientada en el franquismo, cuyo detonante es la representación de la zarzuela El casto José, plagio evidente de La corte de Faraón, en un teatro madrileño con la presencia de un censor en el público. Este, escandalizado por las críticas veladas a la figura del dictador y las constantes referencias sexuales, cancela la obra y envía detenidos a todos los participantes en el espectáculo y a sus responsables a la comisaría de policía, donde el comisario y el propio censor les toman declaración para aclarar los hechos.

El filme se abre, pues, con la detención de los productores y protagonistas de la zarzuela en un teatro de Madrid por parte de la policía, y su traslado a una comisaría. Una vez allí, el censor (un sacerdote) comienza a relatarle al comisario la zarzuela, evidenciando los motivos que lo han llevado a despertarle de madrugada para que tome cartas en el asunto. Es entonces cuando el relato primero o "relato marco" deja paso a un segundo nivel ficcional, constituido por una analepsis o flashback (si utilizamos el concepto propiamente cinematográfico) en el que se muestra la representación escénica de la zarzuela. La voz del cura, que se mantiene unos segundos en off, desaparece para dar lugar a la mostración fílmica del relato enmarcado.

Este tipo de construcción narrativa nos obliga a señalar una concomitancia evidente con la poética valleinclaniana, y también a indagar en cómo García Sánchez presenta una función teatral en el medio cinematográfico, esto es cómo reescribe la zarzuela El casto José de acuerdo con las técnicas del séptimo arte.

En primer lugar, las similitudes de esta estructura narrativa con la 
de Los cuernos de don Friolera (1921) son evidentes: en el esperpento de Valle, Don Estrafalario y Manolito acudían a una representación de la obra de Don Friolera a cargo del titiritero Bululú, y departían entre ellos acerca de cuestiones teatrales, justo antes de que comenzase la obra en sí. Teníamos, así, un primer nivel narrativo (relato marco) donde los personajes de Manolito y don Estrafalario actúan como introductores de un segundo nivel (relato enmarcado), constituido por la historia de don Friolera. En La corte de Faraón, García Sánchez y Azcona utilizan el mismo recurso: el establecimiento de un primer nivel narrativo que actúa como "marco" para el segundo nivel. Desde el relato primero, los protagonistas de la historia van narrando el relato segundo, en el que se encuadra la representación de la propia zarzuela El casto José, que en el relato primero se revela ya, por los comentarios y apreciaciones de los personajes, como un plagio de La corte de Faraón, la cual, a su vez, había funcionado en el momento de su estreno como parodia de Aida. La deformación progresiva de un clásico de la ópera llega en la película a su máxima expresión, ya que el propio argumento de la zarzuela se reproduce en el relato marco, donde se muestra la evidente atracción que Mari Pili (novia del director quien, a la vez, es hijo del empresario que financia la representación) siente hacia el fraile que interpreta el papel de José. Como indica Nadal:

Las dos historias se hallan ligadas narrativa y temáticamente no sólo por formar parte del mismo hilo argumental, y porque los personajes de ambas sean en buena parte los mismos — con las excepciones sobresalientes del cura, del comisario y del empresario-, sino porque lo que se deriva de la oposición entre lo homosexual y lo heterosexual, entre el novio oficial y el novio deseado —aunque inicialmente casto y prohibido-, aparece en las dos historias, con los mismos personajes y con los mismos actores (2002: 440). 
Mediante el evidente juego metaficcional se subrayan las similitudes entre la relación existente en la historia que se desarrolla en el relato marco (Mari Pili enamorada del fraile pese a ser la novia "oficial" de Tarsicio, director y presunto autor del libreto y de claras tendencias homosexuales), y la que tiene lugar en el seno del relato enmarcado, la zarzuela que representan. La inverosimilitud de la historia no parece importar a García Sánchez y a Rafael Azcona y su evidente falta de respeto por el realismo (entendido como voluntad de imitación de lo real) les hace decantarse abiertamente por una estilización hipertrofiada de las formas populares, partiendo de una zarzuela (que a su vez parodia una ópera) para someterla a las torsiones de un supuesto plagio ficticio y, además, reproducirla todavía más hiperbolizada en el relato marco de su película.

\subsection{Teatro dentro del cine}

Laincardinación del estreno de lazarzuela (que tienelugaren el Teatro Martín) dentro del relato enmarcado se va produciendo paulatinamente. Como señala Nadal, este relato marco que los protagonistas cuentan en su reunión de comisaría, no es solamente la representación de la zarzuela sino todo lo ligado a las circunstancias en que se elige el texto y se llevan a cabo los ensayos preparativos: "además de los antecedentes y de algunos pasajes pertinentes de la vida de los protagonistas, están incluidos también en dicho relato enmarcado [...] algunos ensayos de la representación y, sobre todo, la misma representación o lo que, simultáneamente a ésta, sucede en las bambalinas o en la sala" (2002: 440). ¿Cómo traduce, entonces, García Sánchez la zarzuela a lenguaje cinematográfico, cuando es la representación lo que se muestra en el filme?

Santiago Trancón señala nueve características esenciales de la representación teatral, a saber, que es fugaz, irrepetible, reproducible, artificial, artística, intencional, plurimodal, ficticia y real (2006: 246). En este sentido, continúa, el cine "se asemeja a la representación en el momento de la producción o filmación, pero la fragmentación $-\mathrm{y}$ la posibilidad 
de repetición o reversibilidad - de la actuación e interpretación lo separa del teatro" (247). Estas características son compartidas por la zarzuela, pero también hay que tener en cuenta que el género chico mantiene como elementos configuradores de su poética la música y las coreografías, por encima de los diálogos y la acción. En este sentido, la zarzuela puede enmarcarse, por las características del propio género, sin problema bajo los rasgos que Pere Gimferrer asocia al teatro moderno, cuya poética "tiende a centrarse en su identidad visual y gestual antes que en el texto" (1999: 91-92).

Si tomamos como ejemplo de esta transposición la secuencia en que Mari Pili, interpretando a Lota, canta el aria ¡Ay, $b a . . . !$, pueden extraerse algunas conclusiones interesantes sobre los elementos teatrales que García Sánchez privilegia del número musical de la zarzuela para su puesta de relieve en la pantalla. Como se ha señalado algunos párrafos atrás, el principal interés del director salmantino era el de retratar la belleza y la sensualidad de Ana Belén. Pero De la Torre va más allá y le interroga acerca de los pormenores de la grabación del famoso primer plano de esa escena:

JLDT.- ¿Y Ana Belén, es consciente del tipo de plano que se va a rodar?

JLGS.- Perfectamente. Pero no lo hace en función de eso. Además, ese plano lo rodamos incluso con dos cámaras.

JLDT.- Porque es una interpretación muy intensa para un primer plano... Cuando se dice -ya sabes el código este- cuando estás muy en primer plano, como que tienes que estar un poco más frío, más estático. Y aquí Ana Belén se salta todo y dice: al $100 \%$. Y es un acierto.

JLGS.- Eso era la clave del asunto.

JLDT.- Pero erais conscientes de que os estabais saltando el código, ¿no?

JLGS.- Absolutamente. Y esos códigos que dices tú es que 
hay que cargárselos, a cada minuto, desde que el cine ya no es convencional, ahora ya, el cine no es otra cosa que ir cargándoselo (2016: 155).

Esa frialdad, esa impasibilidad a las que alude De la Torre no son más que correcciones que el actor de cine tiene que hacer sobre una actuación, digamos, teatral, debido a la cercanía con que la cámara es capaz de mostrar el rostro, los gestos, la vocalización, etcétera. García Sánchez se refiere al primer plano, largo, sostenido en el tiempo, en que Ana Belén canta mirando fijamente a la cámara cual si estuviera dirigiéndose a los espectadores del teatro, y a cómo la dirigieron para que su expresión facial y corporal fuese exactamente la misma que hubiese sido de estar cantando en un teatro, con el público alejado de ella.

Charles Tesson, a propósito de la comedia cinematográfica muda, realza la "propensión de los actores cómicos [...] a construir a partir de su personaje un imaginario de la escena que parte del rostro vuelto hacia el público con la mirada a cámara y la interpelación gestual como diálogo natural del arte de la mímica" (2012: 17). Este tipo de técnicas actorales, basadas en la exageración de la mímica ante la ausencia del sonido, son equivalentes a las teatrales, puesto que en el rostro y el cuerpo recae gran parte del carácter del personaje. García Sánchez, al pedirle a Ana Belén que recalcase la gestualidad aun a pesar de que la cámara la filmaba en primer plano, está, como él dice, "cargándose el cine”, o, mejor, subvirtiendo los cánones tradicionales de la actuación cinematográfica.

El cine tradicional, con su Método de Representación Institucional, busca la transparencia de la instancia narradora para la creación de un efecto de realismo, de verosimilitud en la narración que permita al espectador recibir la historia que se muestra en pantalla de la manera más directa y efectiva posible. La atenuación de la gestualidad más exagerada del teatro se lleva a cabo para minimizar la afectación y lograr una mayor impresión de realismo; de ahí que García Sánchez, en uno de los cantables más conocidos del género chico español, le pida a Ana Belén que gesticule 
y contonee su cuerpo lo máximo que pueda. La zarzuela, la opereta, la revista, no es realista; como el propio director señala, estos géneros son todo "vistosidad, hedonismo, canto a la vida" (De la Torre, 2016: 154). De ahí su lenguaje hiperbólico, que se torna más deformado si cabe en la versión cinematográfica de este ¡Ay, $b a . .$. ! La mirada directa a la cámara, los fuertes movimientos de carácter erótico, las connotaciones sexuales del lenguaje, la música, la mezcla del largo primer plano con otros planos generales en los que se observa una estilización delirante de la escena a base de luces de colores, sombras y objetos de atrezzo pertenecientes al Egipto Faraónico, hacen de esta secuencia una de las cimas no solo del cine de José Luis García Sánchez sino de la traducción a las pantallas cinematográficas de un género teatral popular como la zarzuela.

En este mismo sentido, pero observando la representación de la obra dentro del relato marco, es preciso utilizar algunas de las reflexiones que Bazin realizaba en los años cincuenta sobre las relaciones entre el cine y el teatro. El crítico francés señala como principal misión del director de cine que traslada una obra teatral a la pantalla la creación de un espacio cinematográfico que sustituya plenamente al teatral, aprovechando las posibilidades narrativas del cine, no sujetas a la simultaneidad de la representación (1990: 188-190). Lo que hacen García Sánchez y su director de fotografía (José Luis Alcaine) en La corte de Faraón es todo lo contrario: filmar teatro. Utilizan, sí, distintos tipos de planos para mostrar la representación de la zarzuela, pero la enmarcan desde un principio en el escenario y aluden, en muchas ocasiones, al público con contraplanos, en el nivel visual, y aplausos, murmullos o risas fuera de campo en el nivel sonoro.

\subsection{La zarzuela y el marco fílmico: una relación de "especularidad compleja"}

Este tipo de presencia del teatro en La corte de Faraón puede encuadrarse en lo que Abuín, siguiendo la definición generalizadora de 
Blüher, denomina como "aquella que tiene como tema el proceso que lleva a una puesta en escena y como protagonistas a todos los agentes que participan en ella" (2005: 139). Pero Abuín continúa y, dentro de esta amplia categoría, establece otras después de analizar con detalle los rasgos de este tipo de filmes; la película que nos ocupa entraría en la de "filmes en los que la inserción de una pieza de teatro actúa como desencadenante para la creación de diversos niveles narrativos y, en consecuencia, para descubrir los mecanismos productores de la ficción” (2005: 140).

José Antonio Pérez Bowie profundiza más en cada una de las tipologías generales presentadas por Abuín y detalla varias subclases de filmes según las características de la presencia del teatro a lo largo de la diégesis. Desde este planteamiento, señala que, en cuanto a los filmes que insertan en la diégesis una representación teatral, las obras pueden agruparse según su nivel de complejidad en casos de "especularidad simple" o "especularidad compleja", entendiendo especularidad como reflejo de la acción teatral (enmarcada) en la acción cinematográfica (marco) (2010: 48-55). La corte de Faraón encajaría, entonces y debido a sus características argumentales, que, como se ha señalado anteriormente, reproducen en el relato cinematográfico los hechos del relato teatral, en el apartado de "especularidad compleja", concretamente en la tipología en la que "la situación de la obra enmarcada se reproduce paralelamente en la obra marco, afectando a la actuación de los personajes de esta" (Pérez Bowie, 2010: 54). Argumentalmente, el paralelismo entre la obra El casto José, zarzuela enmarcada, y la historia de su gestación, ensayo, representación y prohibición fulgurante, es evidente y pone de relieve otro de los puntos más importantes de La corte de Faraón: su puesta en valor de los géneros populares como reflejo fiel de la realidad que los produce.

Es el momento de recuperar alguna de las famosas reflexiones de Ortega y Gasset dedicadas a caracterizar algunos de los tapices de Francisco de Goya y, en general, su obra entera ${ }^{7}$. Se trata del concepto de

${ }^{7}$ Es necesario aclarar aquí que no compartimos la atribución que Ortega hacía de las cualidades del maestro aragonés a una supuesta mentalidad simple y a la dislocación de su 
"plebeyismo", tal y como el filósofo llamaba al fenómeno de la predilección, por parte de las clases burguesas y nobles de la sociedad española de mediados del XVIII, por las formas populares en gestos, trajes, danzas, cantares, diversiones... Según Ortega, esta estilización de las formas populares tradicionales supone una "reestilización" de algo previamente estilizado por el género teatral, que importaba las formas coloquiales y las exageraba para que luego, en un proceso circular, volviesen a ser imitadas por el pueblo (1950: 286).

En La corte de Faraón puede observarse un flujo constante de este tipo de gestualidades, maneras de expresión, relaciones de cortejo, etcétera, entre la historia marco que corresponde al primer nivel diegético y a parte del segundo, y la zarzuela, que como se ha dicho sería una representación teatral enmarcada a su vez dentro del segundo nivel diegético (flashback) que se introduce en a través de una analepsis proveniente del relato marco.

Las formas de cortejo que utiliza Mari Pili con fray José son un buen ejemplo desde el que estudiar estos trasvases entre los dos niveles ficcionales de La corte de Faraón, si entendemos el primero como el cinematográfico y el segundo como el teatral, y asumimos que el primero se corresponde con la "vida" ficcional de los actores que representan su papel en la zarzuela. El caso del personaje interpretado por Ana Belén, Mari Pili, es sustancialmente distinto al de Antonio Banderas, José. Ella está prometida con el hijo de los empresarios de la compañía, cuya homosexualidad se remarca desde el inicio de la cinta. Mari Pili aprovecha su papel en la zarzuela que ha escrito su prometido para desencadenar todos sus encantos femeninos y liberar parte de su libido, ya que, en la realidad cotidiana, su sexualidad se halla reprimida debido a su compromiso con Tarsicio. La zarzuela funciona, de este modo, como ficción a través de la que canalizar sus instintos reprimidos por la situación social en la que se encuentra.

De hecho, durante el primer ensayo en la nave industrial de la

cotidianidad debida a su escalada social desde los ambientes populares a las altas esferas intelectuales. 
periferia $^{8}$ (en el que se cuela la compañía debido a la falta de un local propio para preparar la obra), tras las primeras pruebas, uno de los actores de la compañía, Corcuera, señala ante el carácter más o menos solemne con el que Tarsicio se tomaba su obra que a aquello "hay que echarle picardía, malicia" porque si no, no funcionaría en las tablas. Es entonces cuando la esposa del empresario, embelesada por los "requiebros" del mencionado Corcuera, proclama que "desde hoy, es usted el director". El mentado actor aprovecha, entonces, para incluir todo el lenguaje y las situaciones sicalípticas que caracterizaban a la original La corte de Faraón en esta historia de El casto José. Mari Pili se encuentra, pues, como pez en el agua en las nuevas escenas, en las que tiene que mostrar sus artes en el juego amoroso.

Acto seguido, García Sánchez incluye una secuencia emplazada en el nuevo piso al que se mudará, supuestamente, el matrimonio una vez se haya celebrado la boda. En ella, los padres de Tarsicio, Mari Pili, su madre y un agente inmobiliario ven el apartamento; Azcona y García Sánchez aprovechan entonces para potenciar el significado de la actitud erótica de Mari Pili en los ensayos dejando muy claro que Tarsicio es homosexual o, al menos, que no tiene el mínimo interés en acostarse con su esposa: primero, sugiere que deberían dormir no solo en camas separadas porque “está de moda”, según él, sino que la propia Mari Pili señala que incluso sería mejor hacerlo en habitaciones individuales, lo cual transmite la información de que ella conoce perfectamente las inclinaciones sexuales de su prometido y consiente, de todos modos, llevar la vida que llevan y casarse con él para conseguir una mejor posición económica.

\footnotetext{
${ }^{8}$ Nave que se utiliza, también, para el estraperlo, como era común en los años cuarenta en que está ambientada la película. En la secuencia del ensayo puede observarse cómo varios actores aprovechan cuando no aparecen en escena para robar tabaco de unos ataúdes que hay allí almacenados con mercancías en su interior. La inclusión de ataúdes en muchos relatos de Azcona y en películas de García Sánchez es habitual (el más evidente, en el cuento Los muertos no se tocan, nene y la película del cineasta de título homónimo, estrenada en 2011): "El ataúd es muy de Azcona, muy mío, y muy español. Es que el ataúd es el sitio, por ejemplo, para hacer estraperlo, es el sitio por excelencia para hacer contrabando, para pasar coca..." (De la Torre, 2016: 156).
} 
En un momento dado, la madre de Mari Pili le propina una patada en la entrepierna a Tarsicio (porque, según ella, él querría mandarla a una habitación pequeña con vistas al patio cuando se fuese a vivir con la joven pareja), y este acude con su padre al servicio para "meter los testículos en agua fría" y así calmar el dolor. Sin embargo, cuando padre e hijo se quedan solos en el baño, tiene lugar la escena más desagradable del filme, en la que el rasgo de "selección de materias bajas" que Gargano (2006) atribuye a una parte de la obra quevediana y que constituye uno de los sustratos fundamentales de la poética del esperpento adquiere especial relevancia ${ }^{9}$. El padre de Tarsicio, don Roque, le baja los pantalones y procede a introducir los testículos de su hijo en el agua fría, pero cuando lo hace, se queda sorprendido y se pone las gafas, lo que denota, junto a sus gestos, una aparente dificultad en la tarea de localizarlos. El padre continúa observando los genitales de su hijo (que no se muestran al público puesto que es la expresión del progenitor la que aparece en primer plano) hasta que exclama: "Pero entonces tu... ¡no descapullas!”. El hijo, visiblemente avergonzado, le pide por favor que no siga tocándole ahí abajo ya que le está provocando dolor, pero el padre, henchido de razón, le manda callar y le pide que confíe en él, que eso se arregla en un momento. Entonces, le ordena que, a su voz, "tire" con él hacia atrás, y se produce la sanación: “¡Ves, hijo! ¡Ya está! ¡Totalmente descapullao!”. Por medio de la exageración (esta escena íntima entre padre e hijo que se acaba de resumir es uno de los ejemplos más hiperbólicos del cine de García Sánchez) se aumenta la explicitud del humor picante que de por sí existía en la zarzuela, pero mucho más atenuado.

Mari Pili, recordemos, en El casto José interpreta a la mujer de Putifar, un general del ejército Faraónico que ha llegado de la guerra con una mutilación en los genitales debido a una herida de flecha; en la ficción marco, regenta una pensión familiar con su madre en la que pernoctan artistas de ínfima categoría. En la zarzuela, el personaje de Mari Pili entra en amores con el esclavo José, que le compra Putifar para satisfacerla; en

${ }^{9}$ Para más información, véase Bozal Fernández (1980) o Lorenzo Rivero (1998). 
la ficción marco, la propia Mari Pili comienza a manifestar su atracción por el fraile José en su pensión, primero, y en los ensayos y la propia representación después, ya que aquel ha sido enviado por el obispo para vigilar la puesta en escena y censurar cualquier comportamiento inadecuado, aunque este termine representando el papel del "casto José", cuyo nombre comparte. Así, "la comisaría es el trasunto de una zarzuela desbarajustada, la zarzuela es un trasunto de la enredada vida de sus reclutados actores y ésta el trasunto de un melodrama asainetado" (Sánchez Salas, 1997: 868).

La situación del personaje interpretado por el fraile en la obra es, al igual que la de Mari Pili, paralela a la de su vida real. Si bien la muchacha vive una vida que no la satisface sexualmente, en la representación Mari Pili se siente liberada al interpretar un personaje que sí puede mostrar libremente su sexualidad. En cambio, aunque la situación de José en la ficción marco también es la misma del personaje que representa en la ficción teatral esta no le facilita la liberación de sus pulsiones sexuales debido a la castidad que le imponen sus votos monásticos.

Desde el momento en que el fraile llega a la pensión, Mari Pili debe cederle su habitación por no haber otra libre; ella le observa desde una ventana de la alcoba contigua mientras él, al sentirse solo en el cuarto privado de una mujer joven y atractiva, abre los cajones de la cómoda donde guarda su ropa interior $y$, con gesto compungido pero excitado, olfatea unas bragas. Mari Pili, que lo contempla desde el ventanuco dada la atracción que sintió por él nada más conocerlo, se excita también, y ambos actores destacan, a través de su gestualidad, el deseo sexual que los consume: José no se entrega a él por su condición de fraile y Mari Pili, por estar prometida con un homosexual con el que no mantiene relaciones. Los suspiros, caídas de ojos y movimientos de ambos actores van en la línea de la interpretación teatral; gestualidades que luego repetirán del mismo modo en la obra, especialmente en el número musical en que Mari Pili intenta seducirlo. Ambos personajes del relato marco están poniendo de relieve, en el relato teatral enmarcado, sus sentimientos verdaderos.

Escenas como la accidental visión de los genitales del "casto José” 
presente en la opereta, por parte de la esposa del Faraón y de Lota, con sus consecuentes gestos y comentarios de sorpresa y admiración, funcionan como reflejo hiperbolizado, deformante, del marco ficcional: es en realidad Mari Pili la que está observando los genitales del fraile y admirándose ante algo que aparentemente jamás ha visto (o hace tiempo que no ve) en su vida real. La corte de Faraón es un ejemplo más entre otros filmes en los que la historia de la ficción marco interfiere con la de la ficción enmarcada.

\subsection{La multiplicidad de narradores y la sátira}

La variedad de puntos de vista que adopta el meganarrador10, al menos superficialmente, obedece a la voluntad de reproducir el flashback desde el mayor abanico de miradas posible: de este modo, comienza relatando el estreno el cura censor; después, continúa el dueño de la compañía amateur, don Roque (interpretado por Fernán-Gómez), que se remonta a los orígenes de la redacción de la obra, al haber sido escrita por su propio hijo; más tarde, toma el relevo el novio homosexual de Tarsicio, personaje interpretado por Juan Diego, y comienza a relatar los ensayos; más adelante, es Mari Pili la que cuenta, en confesión al cura, la intromisión del fraile José en la obra; luego, cuando el relato marco alcanza cronológicamente el estreno enmarcado de la zarzuela, el fraile José narra la historia desde su punto de vista hasta que el censor se lo lleva de las orejas, literalmente, por sus pensamientos libidinosos; tras ello, Tarsicio relata los pormenores de la detención con la que se iniciaba la película $y$, por último, uno de los actores de la compañía (interpretado por Luis Ciges) destapa las vergüenzas (o, mejor, quita las máscaras) e informa sobre las ideas anarquistas de don Roque, el empresario, la relación homosexual que mantiene Tarsicio con su amigo Roberto y las infidelidades de Fernanda, la esposa de don Roque; todo ello englobado en la rememoración de la última fiesta de nochevieja en casa de los señores.

Sin embargo, la "superficialidad" de los puntos de vista a la que

\footnotetext{
${ }^{10}$ Tomamos el término con el que Gaudreault y Jost (1995) se refieren al narrador fílmico.
} 
aludía líneas arriba se debe a que el director no respeta, en absoluto, esos puntos de vista en cuanto a la focalización (es decir, lo que el narrador homodiegético sabe acerca de la historia) y el relato está lleno de lo que en términos genettianos se conoce como paralipsis, esto es, infracciones en la coherencia focal (Genette, 1989). Por otra parte, estas "figuras informantes" (Casseti y di Chio, 2010) cumplen simplemente esa función sin que el meganarrador se adapte a las restricciones naturales que sus relatos deben tener. Se produce entonces una ruptura de las leyes del punto de vista, exactamente igual que Quevedo rompe ese molde de la focalización para proponer otra poética diferente a la del género picaresco canónico, el cual presenta como rasgo principal la adopción de una perspectiva intradiegética en la que el protagonista narra retrospectivamente su vida para que el lector reciba la información de modo restringido; es decir, sin conocer hechos que el narrador actor no hubiese vivido, visto o conocido de alguna manera. Don Pablos, por el contrario, en numerosas ocasiones rompe las leyes del punto de vista y presenta hechos al lector que dislocan esas normas, exactamente del mismo modo que se dislocan en La corte de Faraón $^{11}$.

Por ejemplo, de la fiesta de nochevieja, que relata el bolchevique, personaje secundario, actor de la compañía, interpretado por Luis Ciges, se muestran muchas escenas en las que el propio Ciges no está presente. En la que se descubre finalmente que Tarsicio es homosexual debido a que se besa con su amigo Roberto (interpretado por Juan Diego) en medio de un baile, el espectador contempla cómo mientras Mari Pili baila con fray José en actitud de coqueteo, su prometido baila con otro hombre junto a ellos, y ambas parejas se besan a la vez. El bolchevique no asiste a toda la acción, sino que tan solo ve, accidentalmente, el momento final en que todos se besan, para terminar exclamando: “¡Esto es la descojonación!”; sin embargo, el meganarrador ha colonizado al "informador accidental" y, una vez diluida su voz en off en el flashback, toma las riendas de la

\footnotetext{
${ }^{11}$ Remito al estudio de Rico (2000) sobre el punto de vista para profundizar en las diferencias narrativas que provoca el punto de vista entre el Buscón y el Lazarillo.
} 
mostración y desplaza a aquel para gozar de mayor libertad a la hora de configurar el relato.

Desde este planteamiento, la fiesta de nochevieja se convierte en una especie de banquete semejante al que se produce en casa de Alonso Ramplón en el Buscón. A partir de la confesión del bolchevique, que comienza a narrarle la celebración al comisario para demostrar que don Roque es en realidad un ácrata, partidario del amor libre, García Sánchez rompe la focalización interna (como ha venido haciendo a lo largo de todo el relato, con cualquiera de los "informantes" que utilice como punto de referencia) y aprovecha todas las posibilidades del lenguaje fílmico para mostrar la verdadera cara de los protagonistas a través de la hiperbolización de sus comportamientos y, sobre todo, alcanzar una estética verdaderamente grotesca que todavía no tenía parangón en toda la obra anterior del cineasta.

La fiesta, en la que participan todos los pensionistas que se alojan en el negocio de la madre de Mari Pili junto a los componentes de la compañía de teatro, se presenta como un ambiente propicio desatar las fantasías sexuales de cada uno. Por una parte, la pareja Mari Pili-Tarsicio tiene su particular aventura junto a sus respectivos amantes, como se ha indicado más arriba. Por otra, don Roque y su esposa Fernanda se dedican también a satisfacer sus fantasías: el primero negocia con unas prostitutas trillizas el precio que le cobrarán no solo a él sino a otros dos compañeros para acostarse con ellos, después de haberle confesado en un brindis al bolchevique: "Yo soy un ácrata sentimental. ¡Por un mundo sin dios y sin amos!". Su mujer, en cambio, aprovecha la situación para irse a la cama con Corcuera, el actor al que había encomendado la dirección de la obra para que introdujese los cambios picantes después del primer ensayo; pero no solo se acuesta con él, sino que, en el momento en que es descubierta por don Roque (el bolchevique lo avisa de que su esposa está en la cama con otro), no solo aparece Corcuera junto a ella sino que saltan de entre las sábanas cuatro o cinco enanos circenses huéspedes de la pensión. Y como colofón, cuando don Roque le pregunta qué está haciendo, ella le contesta: 
"Jugando a Blancanieves y los siete enanitos".

La presencia de los enanos nos retrotrae a la pensión, ya que, en un momento anterior a este flashback, en concreto en uno de los segmentos narrados por el "informador" fray José, mientras él y Mari Pili juguetean con los pies por debajo de la mesa (recuérdense los similares juegos de Las truchas, obra de 1978), toda la cuadrilla de enanos entra en la pensión formando parte de una comitiva navideña en la que los artistas están disfrazados para representar el Belén. García Sánchez nos los presenta a todos cantando la Marimorena, villancico popular, y hace hincapié en la figura del niño Jesús, al que retrata en primerísimo primer plano mostrando que está interpretado por un enano sin dentadura.

Este tipo de inclusión de enanos en la obra remite, sin duda, a la presencia que estos han tenido a lo largo de la literatura y de las artes pictóricas en las estéticas grotescas. Del mismo modo que Valle unificó, para Divinas palabras, en la figura de Laureano toda la miseria moral de un pueblo ignorante y cruel, Goya representaba a los duendes en sus grabados con aspecto de enanos deformes, como se puede ver en el Capricho 49, por ejemplo: manos grandes y arbóreas en cuerpos anormalmente pequeños, del mismo modo que Valle incluía la hidrocefalia en Laureano para aumentar el contraste grotesco entre las partes del propio cuerpo. Las personas con enanismo han sido a lo largo de la historia, en algunas culturas, asociadas a los ambientes bufonescos o del espectáculo debido a la extrañeza que provocaba su físico en el público, y que remitía a los desórdenes propios del estilo grotesco (Ziomek, 1986: 14). No hay más que recuperar la película Verbena, de Neville, o pensar en la reciente Blancanieves (Pablo Berger, 2013), en la que la historia se emplaza en la España franquista y la protagonista se enrola como torera en un circo ambulante formado en su mayoría por enanos; o en la más lejana en el tiempo y el espacio pero de elevadísima calidad El silencio (Ingmar Bergman, 1963), en la que la presencia de unos enanos españoles de circo en el hotel donde se alojan la protagonista y su hijo sirve de pretexto para la puesta de relieve de la incomunicación y la extrañeza que provoca en el chiquillo el asistir a los 
juegos y conversaciones de los enanos en un idioma que no conoce.

En el guion se hace referencia, también, a la verbena. Cuando Mari Pili y el fraile José están sentados juntos a la mesa de la cocina de la pensión, antes de entregarse a los juegos eróticos con los pies, Mari Pili le enseña al fraile un álbum con fotografías de su vida. En ellas, aparece un muchacho joven vestido con el uniforme falangista, durante la Guerra Civil. Mari Pili dice: "Mi primer novio. Es que las guerras...". José pregunta: “¿Murió en la guerra?”. Y ella responde: “No. Murió en una casa de mujeres de la vida". Tras pasar esa y otras fotografías de varios hombres con los que estuvo (lo cual es indicativo de que Mari Pili ha sido una joven con bastante actividad amorosa), llegan a otra en la que se ve a otro novio suyo. Mari Pili relata lo siguiente:

MARI PILI.- Un imbécil... ¿Ve esta foto en una verbena? La última que nos hicimos juntos... Cinco minutos después subimos a las barcas, ya sabe, esas que si las mueves bien llegan a dar la vuelta de campana... (Ha subrayado con gestos el movimiento de las barcas). Pues, nada, justo cuando la íbamos a dar, Arturo dijo: "Ahora, sin manos". Solo tuvo tiempo de explicarme algo de la fuerza centrífuga...

FRAY JOSÉ. - (Se atreve a suponer.) ¿Se... cayó?

MARI PILI.- ¿Caerse?... Salió disparado y cuando iba por el aire le dio de lleno un tío enorme que iba en las sillas voladoras... Una cosa tremenda, salió en todos los periódicos... Mire el recorte... (Azcona, 2002: 134).

En primer lugar, se pone de relieve la Guerra Civil, pero no de modo solemne, sino subvirtiendo esa misma solemnidad mediante la comicidad y el humor negro. Que su novio haya muerto en un prostíbulo denota el hábito de los soldados de frecuentar este tipo de establecimientos. A Mari Pili, a quien en un principio puede parecer que le duele la tragedia de la reciente guerra, en realidad lo que le preocupa con ese "Es que las 
guerras...” es que esta había llevado a su novio a los prostíbulos. ¿No recuerda este tipo de subversión de los temas solemnes al Valle-Inclán de Martes de Carnaval? El tratamiento de la derrota de España en la guerra de Cuba y la miseria en la que vivían los desertores y excombatientes es igualmente cómico y despiadado: en Las galas del difunto (1926), Juan Ventolera le roba el traje a un cadáver para, precisamente, ir a un prostíbulo.

En segundo término, se utiliza el escenario más común al que el pueblo solía ir a divertirse en la primera mitad del siglo XX, y que ya había sido retratado por Neville en su mediometraje y por Giménez Caballero, tampoco se olvide, en su corto vanguardista Esencia de verbena de 1930. Pero a la imagen grotesca que de la verbena presenta Neville, o a la carnavalesca que de ella también ofrecían Gutiérrez Solana o Goya (las verbenas modernas son una suerte de reinvención, o de complemento de las tradicionales romerías que pintaron esos dos artistas) le añaden García Sánchez y Azcona un toque aún más grotesco con la muerte inesperada y rocambolesca, por impacto contra una persona obesa que volaba en las sillas giratorias de una de las atracciones. Es evidente el ánimo que muestran los guionistas para la recuperación de este tipo de escenarios populares, pero con otra intención muy distinta a la costumbrista: más que retratar las costumbres o la sociedad española de la época, estas se ridiculizan mediante procedimientos humorísticos subversivos12. No es la Guerra Civil la causante de la muerte violenta de los hombres sino la que provoca que estos frecuenten los prostíbulos, y no es la verbena un mero espacio de recreo popular, sino que en ella pueden suceder los más inesperados y grotescos accidentes.

La crítica a la censura se evidencia a lo largo de todo el filme. De hecho, los personajes se agrupan, desde el inicio de la película, en dos bandos: "censores" y "censurados" (Peláez Pérez, 2003: 159), y el

\footnotetext{
${ }^{12}$ Igual que en Colorín, colorado, la paella tiene en La corte de Faraón su protagonismo: en un momento del interrogatorio, don Roque encarga una paella para doce que se comen tan solo él, su esposa, su hijo, el comisario y el censor (la crítica a las clases elevadas es evidente). Por cierto, que Roque también apremia a los convidados a que se la coman pronto porque si no, "se pega el arroz", tal y como ocurría en Colorín, colorado.
} 
filme se construye en torno a estos dos polos, aunque, en el fondo, los guionistas los presenten a todos con el mismo halo miserable a través de la distorsión caricaturesca. La figura del cura censor, Padre Calleja, y del comisario Ramírez (interpretados respectivamente por Agustín González y José Luis López Vázquez) representan la cerrilidad y la hipocresía de dos estamentos: el militar, símbolo del régimen (la policía), y el eclesiástico, el otro pilar en que se apoyaba la dictadura franquista. El comisario Ramírez es ridiculizado desde el inicio al presentarse allí, en medio de la noche, con el pijama por debajo del traje, y sigue siendo caricaturizado desde el instante en que Fernanda, esposa de don Roque, aparece por la puerta. Él babea por ella y la corteja delante de su marido, ante lo que Fernanda parece disfrutar y Roque, mostrar una absoluta indiferencia. De hecho, hay un momento clave en que este cortejo expande sus límites satíricos:

PADRE CALLEJA. - Pero, ¿esto qué es, una comisaría o una casa de pu...? (Se da un manotazo en la boca). Perdón, Dios mío... (Al Comisario). iProsiga el interrogatorio y deje de requebrar a esa señora!

(Roque defiende su honor. A su manera: exagerando su candidez, se maravilla ante el Comisario).

ROQUE._-Pero... usted... no ha requebrado a...

FERNANDA.- (Muy en mujer de mundo). La galantería lógica en un caballero español... (Azcona, 2002: 16-17).

Los españoles, los “caballeros españoles", confunden galantería y mala educación con lo que hoy en día podría considerarse como acoso sexual sin ningún género de dudas; y las mujeres, también. Es esta otra deformación más de las formas populares: gestos, expresiones y modos de relacionarse que como indicaba Ortega, habían sufrido una reapropiación por parte del pueblo a partir de la zarzuela, la revista y de espectáculos como el toreo. El caso de Fernanda con Ramírez supone una transposición de esos modos hiperbólicos de la zarzuela a la ficción fílmica; la esposa del 
Faraón a la que Fernanda interpreta en la obra también quiere seducir al casto José para acostarse con él, utilizando las mismas técnicas de las que se vale en comisaría para seducir al comisario, o de las que se había valido a lo largo de los ensayos para terminar en la cama con Corcuera.

\section{CONCLUSIÓN}

Como se ha visto en esta revisión de La corte de Faraón, Azcona y García Sánchez, desde el guion mismo, utilizan materiales presentes en los géneros populares para deformarlos mediante el lenguaje cinematográfico y componer así una sátira sobre la dictadura franquista y, en especial, la censura. No puede olvidarse que la película está concebida como un flashback debido a que, en realidad, la historia de los personajes y de la preparación, estreno y posterior prohibición de la zarzuela se cuenta retrospectivamente a un censor y un comisario para evitar el ingreso en prisión de sus responsables.

Esta estructura circular lleva a García Sánchez a jugar con la temporalidad del filme (la narración cronológica de un segundo relato analéptico, en el que se enmarca una representación teatral, a partir de distintos narradores "informantes" del primer relato). El trasvase de comportamientos, actitudes y caracteres entre una representación y la otra evidencia ese tránsito de formas estilizadas populares al que aludía Ortega entre la vida cotidiana de los españoles en el siglo XVIII y las artes del entretenimiento.

A partir de otra reestilización de esos modos, y de su hiperbolización (recuérdese la escena en la que Roque provoca que su hijo descapulle, o las actitudes obscenas de Fernanda tanto en la zarzuela como en el relato marco, o los juegos eróticos entre Mari Pili y Fray José, etcétera), el director castellanoleonés presenta una crítica muy ácida a una sociedad española que, especialmente durante los años cuarenta, sufría una fuerte represión de sus libertades no solo artísticas sino a todos los niveles. Este tipo de condicionantes políticos producían situaciones absolutamente 
inverosímiles, como que los propios censores se convirtieran en guionistas de las obras que censuraban para asegurarse de su viabilidad, y comportamientos hipócritas que se desenmascaraban en cuanto se traspasaba mínimamente la línea que separa lo público de lo privado. El uso de la comicidad, en este caso de lo que Berlanga denominaba "humor español", aplicado a situaciones comprometidas en las que las materias tratadas rozan y traspasan los límites del mal gusto, revelan la corrupción y la hipocresía que latían bajo la cara visible del régimen y su defensa de la religión y las tradiciones.

Todos estos elementos hacen de La corte de Faraón una obra cinematográfica representativa de la Transición española, ya financiada con el apoyo de TVE según las leyes propuestas por Pilar Miró y sin ningún tipo de cortapisa en la libertad de expresión. El uso del lenguaje cinematográfico busca en este filme potenciar no solo las formas originales de la zarzuela sino reescribirlas en un marco semiótico absolutamente distinto. Comenzaba, de este modo, la carrera de García Sánchez como adaptador de materiales previos, y los rastros e influencias de las poéticas quevedianas, goyescas y valleinclanianas comenzaban a tomar una forma definida en su producción.

\section{REFERENCIAS BIBLIOGRÁFICAS}

ABUÍN, A. (2005). "El filme de teatro: arte frente a industria, o totus mundus agit histrionem". Anthropos 208, 138-151.

AZCONA, R. y GARCÍA SÁNCHEZ, J. L. (2002). Guion cinematográfico. La corte de Faraón. Alicante: Biblioteca Virtual Miguel de Cervantes.

BAZIN, A. (1990). ¿Qué es el cine? Madrid: Ediciones Rialp.

BENET, V. J. (2012). El cine español: una historia cultural. Barcelona: Paidós. 
BOZAL FERNÁNDEZ, V. (1980). “Quevedo y Goya”. Cuadernos Hispanoamericanos 361-362, 112-131.

CASTRO DE PAZ, J. L. y PENA PÉREZ, J. (2005). "Variaciones sobre la incertidumbre (1984-2000)". En La nueva memoria. Historia(s) del cine español (1939-2000), J. L. Castro de Paz, Julio Pérez Perucha y Santos Zunzunegui (eds.), 254-314. A Coruña: Vía Láctea.

CASSETI, F. y DI CHIO, F. (2010). Cómo analizar un film. Barcelona: Paidós.

DE LA TORRE GARCÍA, J. (2016). José Luis García Sánchez. El humor como bicarbonato. Madrid: Notorious Ediciones.

ESPÍN TEMPLADO, M. P. (1995). Teatro por horas en Madrid (18701910). Madrid: Instituto de Estudios Madrileños.

GARGANO, A. (2006). "La novela picaresca entre realismo y representación de la realidad: el caso del Buscón”. La Perinola 10, 123-131.

GAUDREAULT, A. y JOST, F. (1995). El relato cinematográfico. Cine y narratología. Barcelona: Paidós Ibérica.

GENETTE, G. (1989). Figuras III. Barcelona: Lumen.

GIMFERRER, P. (1999). Cine y literatura. Barcelona: Planeta.

LORENZO RIVERO, L. (1998). Goya en el esperpento de Valle-Inclán. Sada, A Coruña: Ediciós do Castro.

MONTERDE, J. E. (1993). Veinte años de cine español (1973-1992). Un cine bajo la paradoja. Barcelona: Paidós Ibérica.

NADAL, J. M." (2002). "Sobre El baile, La corte de Faraón, La señorita de Trevélez y Calle Mayor". En Del teatro al cine y la televisión en la segunda mitad del siglo XX, José Romera Castillo (ed.), 437446. Madrid: Visor Libros.

ORTEGA Y GASSET, J. (1950). Papeles sobre Velázquez y Goya. Madrid: Revista de Occidente.

PELÁEZ PÉREZ, V. M. (2003). "Caricatura en La corte de Faraón, de J. L. García Sánchez”. Garoza: Revista de la Sociedad Española de Estudios Literarios de Cultura Popular 3, 153-177. 
(2003b). "La Corte de Faraón” desde la perspectiva paródica. Alicante: BIMICESA.

PÉREZ BOWIE, J. A. (2010). "La teatralidad en la pantalla. Un ensayo de tipología”. Signa. Revista de la Asociación Española de Semiótica $19,35-62$.

RIAMBAU, E. (1995). “La década socialista (1982-1992)”. En Historia del cine español, Román Gubern (ed.), 399-437. Madrid: Cátedra.

RICO, F. (2000). La novela picaresca y el punto de vista. Barcelona: Seix Barral.

ROMERA CASTILLO, J. (ed.) (2016). Teatro y música en los inicios del siglo XXI. Madrid: Verbum.

TESSON, C. (2012). Teatro y cine. Barcelona: Paidós.

TORREIRO, C. (1995). "Del tardofranquismo a la democracia (19691982)”. En Historia del cine español, Román Gubern (ed.), 341390. Madrid: Cátedra.

TRANCÓN, S. (2006). Teoría del teatro. Bases para el análisis de la obra dramática. Madrid: Editorial Fundamentos.

ZAMORA VICENTE, A. (1969). La realidad esperpéntica. Aproximación $a$ Luces de bohemia. Madrid: Gredos.

ZIOMEK, H. (1983). Lo grotesco en la literatura española del Siglo de Oro. Michigan: BPR Publishers.

Recepción: 10 de enero de 2018

Aceptación: 13 de abril de 2018 